\title{
Rechtsgeschichte
}

http://www.rg-rechtsgeschichte.de/rg3

$\operatorname{Rg} 32003$

$236-237$

Zitiervorschlag: Rechtsgeschichte Rg 3 (2003)

http://dx.doi.org/10.12946/rg03/236-237

\section{Thorsten Keiser}

Dr. Porno Max 


\section{Dr. Porno Max*}

Wenn in Romanen Gerichte vorkommen, geht es meistens um Prozesse. Bei den populären Varianten halten diabolische Staatsanwälte gnadenlose Plädoyers gegen unschuldige Angeklagte (jung und weiblich), gutaussehende Strafverteidiger (jung und männlich), die immer gerade ihren ersten Fall haben, fallen ihnen heroisch ins Wort und tragen am Ende den Sieg und die Angeklagte davon. Bei den weniger populären gehen die Prozesse oft schlecht aus. Menschen werden verurteilt, ohne dass sie etwas Böses getan hätten, oder Rosshändler enden auf dem Schafott.

Benno Hurt geht es um viel weniger dramatische Begebenheiten. In seinem Buch »Der Samt der Robe « erweitert er den Blickwinkel auf das, was sich hinter den Kulissen der Justiz abspielt. Ein Gericht wird besichtigt, und alle, die sich darin aufhalten. Hurt, der selbst Richter und Fotograf ist, geht mit dem Teleobjektiv auf die Jagd, verfolgt Richter und Wachtmeister bis in die Besprechungszimmer und Amtsstuben. Gerade bei Konstellationen, für die sich andere Literaten nicht interessieren, drückt er auf den Auslöser. Schauplatz ist das Amtsgericht Regensburg und dort ist, wie bekanntlich überall in Bayern, die Welt noch in Ordnung. Es geht lustig $\mathrm{zu}$, und die Urteile tun genauso wenig weh wie die Operationen in der Schwarzwaldklinik. Man begegnet einer Ansammlung schrulliger Chargen, die an eine Beamtenfarce von Gogol erinnern. Wie dem Richter mit Spitznamen »Dr. Porno Max «, ein auf Herrenwitze versessener Lifestyletrottel, der seinen Kollegen mit augenzwinkernder Stammtischerotik die Schamesröte ins Gesicht treibt. Oder dem Staatsanwalt Professor Bub, der für solche Dinge - wie könnte es auch anders sein - noch nicht reif genug ist. Vom Wachtmeister Biederer bis zur Jugendgerichtshelferin Fürsorg erinnern die sprechenden $\mathrm{Na}$ men an die angestrengten Versuche von Repetitoren, ihren Klienten die dröge Paukerei zu versüßen. Da wandelt eine Russischdolmetscherin, natürlich mit dem Namen Olga, als running gag durch die Erzählungen und darf als Gerichtssexbombe, angekündigt durch das Klackern ihrer Pumps, für libidinöse Hitzeaufwallungen unter den Talaren sorgen. So verdreht sie auch Richter Kurz den Kopf, der, wie auch Hurt, auf Jugendstrafrecht spezialisiert ist und gerne gutem Wein zuspricht. Überhaupt erfährt man Dinge, die man ohnehin nicht wissen will (etwa über die Essgewohnheiten der Wachtmeister oder das Verhältnis des Richters Kurz zu seiner Katze) und dies dazu gleich mehrfach. Vielleicht richtet sich Hurt an ein vorwiegend juristisches Publikum, dem aufgrund professioneller Deformation das Nachschlagen so zur Gewohnheit geworden ist, dass es darüber das Lesen verlernt hat.

Wenn Hurt allerdings zuweilen den volkstümlich-bajuwarischen Frohsinn einmal beiseite lässt, gelingt ihm durchaus auch eine glänzende Momentaufnahme. So beschreibt er, wie einem Wachtmeister, der nach einer Bombendrohung im Gerichtsgebäude allein zurückbleibt, die Ballade von John Maynard ins Gedächtnis kommt, während er auf den Koffer mit der Sprengladung zugeht. Leider sind solche prägnanten Passagen, die durchaus eine innere Spannung haben, eher eine Rarität. Zu oft wird gewaltsam auf Lacher gezielt. Fast jede Erzählung soll ein humoristisches Feuerwerk zünden, aber nicht selten gehen die Schüsse daneben.

\footnotetext{
* Benno Hurt, Der Samt der Robe.

Erzählungen aus der Justiz,

Viechtach: Lichtung-Verlag 2002,

208 S., ISBN 3-929517-58-2
} 
Meist liegt das auch an den spröden Gegenständen, denen sich Hurt zuwendet. Themen wie die Überlegenheitsgefühle eines Zivilrichters gegenüber einem Strafrichter oder das Verhältnis zwischen Berufs- und Laienrichtern sind, da mag sich die Sprache bemühen wie sie will, literarisch-satirisch schwer verwertbar.

Manche der Erzählungen sind weniger darum bemüht, soziologische Rollenbilder von Gestalten aus dem Gerichtsalltag nachzuzeichnen. Die besten von ihnen könnten durchaus den Stoff für eine Gerichtsszene der Serie Liebling Kreuzberg abgeben. Doch die Drehbücher Jurek Beckers leben im Wesentlichen nicht von ihren Justizdarstellungen, sondern vom farbigen Portrait ihrer Hauptperson. Hurts Juristenfiguren sind dagegen blasse, holzschnittartige Typen, jeweils mit zwei oder drei Charaktereigenschaften ausgestattet, die dem Leser bis zur Ermüdung immer wieder vorgeführt werden. Es geht Hurt auch nicht in erster Linie um die Richter Kurz, Dr. Lex oder den Staatsanwalt Bub. Protagonistin ist die Justiz als solche, verkörpert im Amtsgericht als ihrer banalsten irdischen Erscheinungsform. Und dort gibt es wirklich nicht immer etwas zu lachen. Die Gestalten, die man dort antrifft, sind Normalos mit einem ziemlich langweiligen Alltag. Man könnte ihnen in jedem beliebigen Büro einer Feuerversicherungsgesellschaft oder Stadtverwaltung begegnen. Richter sind eben auch nur Menschen. Sie sitzen nicht ihr ganzes Leben lang als kühle Spruchkörper einer ratio scripta in entrückter Ferne hinter ihrem Holztresen im Gerichtssaal, sondern haben auch ihre Probleme, fahren gelegentlich zu schnell mit dem Auto, wissen nicht mehr weiter, sind nervös, neigen zur Pornographie oder kommen nach einer Weinprobe verkatert in die Geschäftsstelle. Dieser Grundton ist in vielen der Erzählungen spürbar und eine Art Leitmotiv des Buches. Das wusste man aber schon vorher und allein diese Erkenntnis macht die gutmütige Skizze eines Amtsrichters von seinem Biotop noch nicht literarisch interessant. Die Vorzüge des Buches liegen erstens in seiner unbestreitbaren Originalität und zweitens auf einer eher dokumentarischen Ebene. Hurt dringt in Räume vor, die der Literatur sonst so verschlossen waren wie die Beratungszimmer für alle außer den Richtern. Wer also ein brennendes Interesse an der Physiognomie eines Amtsgerichts hat, wird hier viel Anschauungsmaterial finden. Regensburg könnte überall sein, und einigen der Personen, die Hurt vorführt, könnte man auf den Gerichtsfluren zwischen Flensburg und Füssen auch in Wirklichkeit begegnen. Dennoch muss man Heribert Prantl, sofern er den Erzählungsband mit dem etwas pathetischen Wunsch, das Buch möge »im Schoß der Justitia liegen ", in den Rang einer juristischen Pflichtlektüre heben will, ausdrücklich widersprechen. In den Schoß der Justitia gehört immer noch der Schönfelder!

Thorsten Keiser 